\title{
Poemas de Zang Kejia e Ai Qing
}

Milena de Moura Barba

\section{Sobre as traduções}

A tradução de poesia chinesa para língua portuguesa ainda é escassa, some-se $\mathrm{a}$ isso o fato de que a maioria das obras encontradas dedicam-se à poesia clássica chinesa, envolvendo textos de cerca de X século a.C. até o século XVII. $\mathrm{E}$ a escolha dos poemas aqui apresentados se justifica por oferecer ao leitor uma pequena mostra da poesia chinesa do século XX.

Os poemas apresentados foram traduzidos diretamente do chinês moderno, e constituíram-se em meio a um processo de leituras, escritas, releituras, reescritas e pontos finais. As diferenças entre a língua chinesa e a língua portuguesa se escancaram, se diluem, se motivam e implicam uma série de escolhas, sobre as quais este texto procura se deter. O primeiro processo foi de uma leitura seguida de tradução, no nível do vocábulo, do verso, da estrofe e do poema. A tradução da palavra, elencando as suas suas possibilidades de sentido implícitas o cerceamento do sentido dentro do verso, sua relação dentro da estrofe, do poema. Por fim, também levamos em conta alguns elementos externos na escolha, como por exemplo o caso do poema 墙 qiáng, que optamos por traduzir como muro ao invés de parede, para estreitar a ligação com o período pelo qual passava a Alemanha no momento em que o poema foi escrito.

Vejamos, por exemplo, o verso do poema de Zang Kejia “俯下身子给人 民当牛马 fǔ xià shènži gěi rénmín dāng niúmă”, acompanhando o percurso apontado acima, a palavra “俯下 fŭ xià” significaria abaixar-se, abaixar a cabeca em sinal de respeito, mas também traz o sentido de vertigem, tontura de cabeca; “身子 shēnzi” traz o sentido de corpo humano, gravidez; “给 gěi” [dar / para]; “人民 rénmín”, [povo]; “牛马 niúmă”, [burro de carga - composto pelos caracteres de boi e de cavalo]. Ele é antecedido pelo verso “有的人 yǒu de rén”, que pode ser 
traduzido como "existem pessoas que", ou como "algumas pessoas". A primeira versão da tradução seria "abaixadas, são do povo burro de carga".

Uma das outras traduções elencadas para o primeiro verso seria "a vertigem, condescendência humana, faz do povo burro de carga", uma opção que trabalha com os sentidos implícitos de cada uma das palavras, buscando compor o sentido geral do verso e se distanciando da fala prosaica.

A tradução final busca fortalecer a continuidade com os versos anteriores da mesma estrofe, através da consonância das consoantes nasais $m$ e $n$, da inclusão do pronome possessivo seu, ainda que exclua a repetição do vocábulo povo:

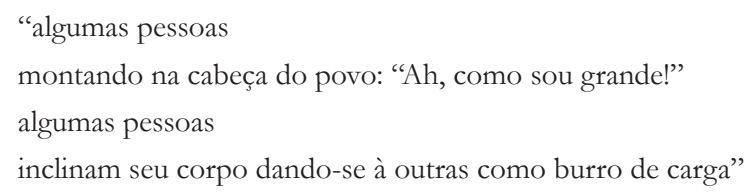

Vejamos também algumas soluções encontradas no poema “墙 qiáng”, de Ai Qing. comentando um pouco de diferenças formais entre a língua chinesa e a língua portuguesa.

$\mathrm{Na}$ segunda estrofe do poema, os caracteres “高 gäo", “厚 hòu”, “长 cháng” irão aparecer em diversos versos do poema. Em uma primeira tradução “高 gāo" pode significar alto, altura, elevado; o caractere “厚 hòu”, grosso, espessura, generoso, profundo e o caractere " “长 cháng", comprimento, longo, ponto forte. Ao longo do poema eles foram traduzidos de duas formas diferentes, como adjetivos, alto, espesso e longo e como substantivos, altura, espessura e alcance. Vamos comentar o caso específico das traduções da "长 cháng" ao longo da segunda estrofe do poema:

No terceiro, no quarto e no quinto verso da tradução, optamos pela utilização do substantivo longo ao invés de comprido, pois buscamos trabalhar com a abertura das vogais nas palavras. Em ambos os versos as três palavras supracitadas aparecem em sequência, temos a palavra alto composta pela vogal aberta $a$ e a vogal fechada $o$ depois a palavra espesso, vogal semifechada $e$, vogal semifechada $e$ e a vogal fechada $o$, e por fim a palavra longo, com duas vogais fechadas o. Realizando assim um progressivo fechamento na abertura da boca da vogal aberta, a, até a vogal fechada, $o$.

A tradução realizada no terceiro verso e no décimo primeiro verso do caractere "长 cháng", resultou no substantivo "alcance". A escolha do substantivo "alcance" em detrimento do substantivo "comprimento" foi realizada levando em 
conta dois âmbitos: Um deles diz respeito à consonância com a palavra espessura, através da fricativa s. O outro diz respeito ao sentido da palavra, "alcance" compartilha com a palavra "comprimento" uma possibilidade de sentido ligada à distância, implicando também um sentido de distância a ser vencida e, ao mesmo tempo, compartilha com o caractere "长 cháng" o sentido de força da capacidade, potência do talento, próximo à alguns significados possíveis do mesmo caractere. Em última instância, levou-se em conta o percurso do próprio poema que, ao final desta mesma estrofe irá iniciar uma série de questionamentos sobre o alcance da contenção realizada pelo muro.

Ainda na segunda estrofe iremos comentar a tradução do verso “又怎 能阻挡 yòu zèn néng zǔ dăng”. Formado pelo caractere “又 yòu” [conjunção e], “怎, zénn” [como] “能 néng” [pode - ter capacidade para], unidos significando “como é possível”; “阻挡 zǔdăng” [parar, impedir]. Neste caso optamos por iniciar o verso com a expressão "e ainda", buscando reiterar os componentes de repetição, adição, superação, presentes ao longo do poema nos caracteres “ 再 àì", “更 gèng” e “又 yòu”. Outra escolha implicada na tradução deste verso diz respeito ao tempo verbal. Optamos pela tradução "E ainda como poderia impedir", por reafirmar o caráter de questionamento hipotético, a despeito das opções "como pode impedir" no presente do indicativo, ou "como é possível", que trazem este componente de forma não explícita. No âmbito das escolhas e processos genéricos, observados ao longo do trabalho de tradução ainda é importante citar que, em alguns casos, o chinês moderno possui referências à língua chinesa clássica. Ainda que possua diferenças fundamentais diante dele, como seu caráter dissílabo em contraste com o caráter monossilábico da língua clássica é relevante salientar dois aspectos:

O primeiro deles diz respeito à tradição antiga, em que narrativas ou sentidos mais complexos podem ser remetidos pela junção de 3, 4, 5 caracteres, dentre outras formações possíveis. O chamado成语chéngyǔ, colocações fixas e espécie de provérbios, tem suas raízes na literatura clássica, mas ainda hoje está presente e é compartilhado em situações cotidianas, sendo encontrado reiteradamente na literatura moderna e contemporânea. Por vezes a tradução de cada vocábulo não atingirá um sentido próximo em língua portuguesa, embora possa existir um provérbio com sentido semelhante em língua portuguesa formado por palavras que não as mesmas encontradas na tradução de cada ideograma. Nos poemas aqui apresentados não foram encontrados nenhuma conexão com os 成语chéngyŭ, mas um levantamento específico de acordo com o contexto foi necessário.

No caso da expressão “自由自在地 zìyón zì ài di”, ainda que ela não seja classificada como um 成语chéngyŭ, ela é uma colocação e por isso optamos por 
traduzi-la com uma expressão também comum em língua portuguesa: "livre e desimpedida".

$\mathrm{O}$ segundo aspecto diz respeito às escolhas de tradução e reescritas do poema. A língua chinesa tem uma riqueza de composição muito grande. Se tomarmos como exemplo um ideograma de um texto clássico, os significados que ele encerra podem ser inúmeros, e uma tradução para o português provavelmente não se resumiria a uma única palavra. No chinês moderno, diferentes palavras compostas por dois caracteres, compartilham um caractere em comum, embora signifiquem coisas diversas, um exemplo é a expressão “踌躇满志 chóuchú-mănそhì”, encontrada no poema "As pombas de Viena".

No chinês moderno a palavra 踌躇chóuchú [hesitar] compõe outras expressões, como 踌躇不决 chóuchú [hesitar] - bù [não] - jué [decidir], com significado próximo à palavra [indeciso]; e também 踌躇不安 chóuchú, [hesitar] - bù [não] än [seguro, quieto], chóuchú-bùān [intranquilidade]; com as quais compartilha esse componente semântico de hesitação. O caractere 满 măn [cheio, pleno, inteiro, atingir], também compõe a expressão, como em 自满 qì [si] - măn, [satisfeito] complacente, zimăn [satisfeito consigo mesmo]; 满怀 măn [repleto] - buái [coração, mente], mănhuái [imbuído de]; e por fim o caractere 志 z̧bi [ideal, desejo], o mesmo encontrado em 意志 $y i$, [sentido] ₹bi [ideal, aspiração] como nas palavras [desejo, determinação].

A tradução da expressão 踌躇满志 chóuchú-mănそhì, envolveu uma série de escolhas. Essa expressão compartilha significado com a nossa palavra complacência, mas difere, pois traz a noção de uma complacência consigo mesmo, ela também se relaciona com a palavra orgulho, presunção, compondo um sentido de orgulho complacente de si próprio. Levando em conta as leituras e relações supracitadas optamos pela utilização de uma expressão, compondo o verso sen orgulbo complacente.

A tradução caractere por caractere, muitas vezes pode levar a uma construção poética muito interessante, pois se situa fora da linguagem cotidiana e, portanto, permite que a linguagem poética se manifeste naquilo que lhe é mais próprio: a possibilidade de subversão da fala comum.

No entanto, considerando que estes dois autores, em particular, têm uma motivação criativa fortemente influenciada pelo Movimento Quatro de Maio de 1919, marco do início do movimento comumente chamado de 新文学 Xín wénxué [Nova Literatura], que recusava a rígida versificação característica da poesia clássica, em sua harmonia, rimas e paralelismos característicos em prol de uma linguagem prosaica, cotidiana, que buscava expressão em versos livres, optamos aqui por soluções que mantivessem um contato fluido com a forma prosaica da 
língua portuguesa do Brasil o que esperamos ter exemplificado com os exemplos comentados ao longo desta apresentação.

A título de informação, saliento que essas traduções se inscrevem em um projeto de maior fôlego: a realização de uma antologia de poesia chinesa do século XX a ser publicada pela editora Annablume (São Paulo), na coleção Lingua, Discurso e Literatura.

Por fim, agradeço à interlocução de colegas que, seja pela fluência no idioma chinês, seja pelo repertório poético, colaboraram no processo de tradução que aqui se apresenta.

\section{Zāng Kèjiā (蔵克家)}

Zāng Kèjià (1905-2004), nasceu em uma área rural da província de Shandong, Sudeste da China, e faleceu em Beijing, Capital da China. Iniciou sua carreira literária motivado pelos eventos do movimento Quatro de Maio de 1919, e sua produção literária sempre foi marcada pela sua participação política. Com uma atividade literária e política de mais de 70 anos é difícil sumarizar sua produção, que abarca obras de poesia, prosa, ensaios e memórias. Também exerceu a função de editor - sendo de sua responsabilidade a edição das poesias de Mao Zedong. No campo político, foi membro da Liga Democrática Chinesa, tendo tomado parte tanto no Comitê Permanente da Assembleia Popular Nacional da República Popular da China, quanto da própria Assembleia Popular Nacional da República Popular da China. O poema traduzido nesta breve antologia é um de seus poemas mais conhecidos: trata de uma homenagem ao $13^{\circ}$ aniversário da morte de $L u$ Xun e, vale dizer, foi escrito no mesmo mês em que Mao Zedong proclamou o estabelecimento da República Popular da China, outubro de 1949.

\section{Algumas pessoas \\ ao Lu Xun, in memorian}

existem pessoas vivas

que já estavam mortas

existem pessoas mortas

que ainda vivem

algumas pessoas

montando na cabeça do povo: "Ah, como sou grande!"

algumas pessoas

inclinam seu corpo dando-se à outras como burro de carga. 
algumas pessoas

gravam seu nome nas pedras a dizer: "imortais";

algumas pessoas

desejam ser grama, esperando o cair da próxima queimada.

algumas pessoas

vivendo outros já não podem viver;

algumas pessoas

vivendo em função do frutificar alheio

os que guiam a cabeça do povo

o povo os depõe

os que se tornam, do povo, burro de carga

serão eternamente lembrados

os que cavam seu nome na pedra

seu nome se decompõe mais velozmente que um cadáver

só é preciso o soprar da brisa da primavera

em toda parte verdeja a grama

daquele que vivo impede a vida alheia

seu fado pode ser visto

aquele que vivo fortalece a vida alheia

a massa o infla, alto, bem alto.

Pequim, outubro de 1949

有的人活着

他已经死了

有的人死了

它还活着

有的人

骑在人们头上：“啊, 我多伟大!”

有的人

俯下身子给人民当牛马。 


\section{有的人}

把名字刻入石头相“不朽” ;

有的人

情愿做野草, 等着地下的火烧。

有的人

他活着别人就不能活;

有的人

他活着为了多数人更好地活。

骑在人民头上的,

人民把他摔垮;

给人民做牛马的，

人民永远记往他!

把名字刻入石头的,

名字比尸首烂得更早;

只要春风吹到的地方,

到处是青青的野草。

他活着别人就不能活的人,

他的下场可以看到;

他活着为了多数人更好地活着的人,

群众把他抬举得很高, 很高。

1949 年10月于北京

\section{Ài Qing (艾青)}

Ài Qīng (1910-1996), pseudônimo de Jiăng Zhènghán (蒋正涵), nasceu na província de Zhejiang, Sudeste da China. Após sua entrada na Academia de Arte de Hangzhou mudou-se para Paris, onde viveu de 1929 a 1932 dedicando- se ao trabalho de pintura de porcelanas, bem como aos estudos de arte, filosofia e poesia moderna ocidental. Voltou à Xangai em maio de 1932, juntou-se à Organização de Artistas de Esquerda e no mesmo ano foi preso por se opor ao Partido Nacionalista (Guoming dang). Poeta, editor de periódicos, e diretor do departamento de literatura da Universidade Yucai de Chongqing, em 1941 mudou-se para Yan'an e filiou-se ao Partido Comunista Chinês, tendo participado intensamente 
de Comitês Culturais e da edição de periódicos de poesia e literatura. Em 1958 foi exilado por autoridades comunistas para a região de Xinjiang e, apesar de não ser proibido de escrever poesia neste período, só em 1979, quatro anos após seu retorno à Pequim e após a derrota da Camarilha dos Quatro, voltaria a publicar. Os três poemas escolhidos do autor datam desta segunda fase. Em 1979, o poeta visitou a Alemanha, e o poema "O muro" obteve crítica excelente.

\section{Esperança}

um marinheiro diz

o que ele mais gosta é do irromper de um levante

aquela espuma branca trazida pelo içar das âncoras...

um marinheiro diz

o que mais o alegra é o que o descer das âncoras transparece

o clamor do romper das correntes...

a partida de uma esperança

a chegada de outra esperança

Shanghai, março de 1979

盼望

一个海员说,

他最喜欢的是起针所激起的

那一片洁白的浪花......

一个海员说,

最使他高兴的是跑锚所发出的

那一阵铁链的喧哗......

一个盼望出发

一个盼望盼望

1979年3月 上海 


\section{Muro}

Ài Qīng

um muro, como uma lâmina

a cortar uma cidade em metades

uma a leste

uma a oeste

qual a altura do muro?

tem qual espessura?

tem qual alcance?

e alto, e espesso e longo

e não é mais alto, mais espesso, mais longo

do que a grande muralha

mas também uma ruína da história

trauma das etnias

ninguém gosta deste tipo de muro

três metros de altura são como nada

cinquenta centímetros de espessura são como nada

quarenta quilômetros de alcance são como nada mil vezes mais alta

mil vezes mais espessa

mil vezes mais longa

e ainda como poderia parar

as nuvens celestiais, o vento, a chuva, os raios de sol?

e ainda como poderia impedir

as asas das aves e o canto do rouxinol?

e ainda como poderia impedir

o fluxo das águas e dos ares?

e ainda como poderia impedir

milhões de pessoas

com pensamentos ainda mais livres que o vento?

com uma vontade ainda mais profunda que a terra?

com aspirações mais duráveis que o tempo?

Bonn, 22 de maio de 1979 
一堵墙, 像一把刀

把一个城市切成两片

一半在东方

一半在西方

墙有多高?

有多厚?

有多长?

再高, 再厚, 再长

也不可能比中国的长城

更高, 更后, 更长

它也只是历史的陈迹

民族的创伤

谁也不喜欢这样的墙

三米高算得了什么

五十厘米厚算得了什么

四十五公里长算得了什么

再高一千倍

再厚一千倍

再长一千倍

又怎能阻挡

天上的云彩, 风, 雨和眼阳光?

又怎能阻挡

飞鸟的翅膀和夜莺?

又怎能阻挡

流动的水和空气?

又怎能阻挡

千百万人的

比风更自由的思想?

比土地更深厚的意志

比时间更漫长的愿望?

1979 年5月 22 日 波恩 


\section{As pombas de Viena}

Ài Qīng

Manhãzinha, todas as pombas alegres e voando agitadamente no alto do campanário nos toldos dos antigos edifícios na capela do castelo cinza -

na tumba da família imperial voando agitadas por todos os lugares...

as pombas de Viena

nunca temeram as pessoas

sob os fícus dos parques

no caminho entre as árvores

na passagem dos turistas

as pombas de Viena

avançando livres e desimpedidas

nada assustadas

como parecem tranquilas

as pombas de Viena

parecem indiferentes

não ouviram os tiros

nem viram o princípio de incêndio

sempre tão serenas

as pombas de Viena são amnésicas

elas também partiram

fugindo para outro lugar

e então voltaram

compelidas pela fome às ruínas

olhando as pombas de Viena

seu orgulho complacente

davam às pessoas um sonho

davam as pessoas uma fantasia

as pombas de Viena voavam determinadas

sobre o violino da escultura de Strauss

e tranquilamente cerram suas asas 
As pombas de Viena

são o peso singelo da nossa época

conservando milhões de desejos de paz

维也纳的鸽子

早晨, 所有的鸽子

都高兴地鼓动着翅膀

维也纳是鸽子的城

在高高的钟楼上

在古老建筑物的窗檐上

在灰色城堡的教堂

皇家的陵墓上

到处鼓动都有鸽子鼓动着翅膀......

维也纳的鸽子

从来不怕人

在公园的菩提树下面

在林间小道上

在喷水池边

在旅游者走过的地方

维也纳的鸽子

自由自在地迈着步子

毫不经

维也纳的鸽子

显得多么镇定

显得莫不关心

好像没有听见过枪声

也没有看见过火灾

永远那么安详

维也纳的鸽子是健忘的

他们曾被打散

逃亡到别的地方

然后又会来

在劫后的废墟上寻找找食粮

看着维也纳的鸽子

踌躇满志的模样 


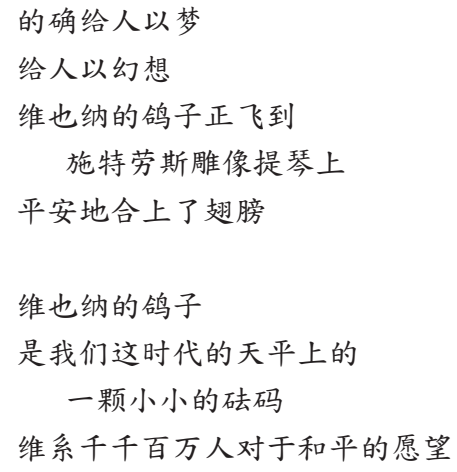

\section{Referência}

HAN, Zuorong (org.). Xìn Zhōngguó liùshí nián wénxué dà xì. Shigēèing xuăn. [Nova série de poesia chinesa dos últimos 60 anos. Poemas Escolhidos]. Wuhan: Editora de arte e literatura Changjiang, 2009. 